\title{
Spinal fractures associated with ejection from jet aircraft: two case reports and a review
}

\author{
M. R. JAMES
}

Department of Accident and Emergency, Lincoln County Hospital, Lincoln, England

\section{SUMMARY}

Virtually any A\&E department in the UK may see aircrew who have ejected. The case histories of two pilots who ejected and sustained spinal fractures are presented. Both had minimal back symptoms and walked from the site of landing. All ejectees should be considered to have a spinal fracture until proven otherwise radiographically. Other injuries that these patients may sustain during ejection are also discussed.

\section{INTRODUCTION}

Military aircraft operate in nearly all areas of this country, so any A\&E department may be called on to treat aircrew who have ejected. Little has been written in the civilian literature since the 1960 s about the injuries that these patients may have sustained. Within an 8-month period at Lincoln, four Hawk fast jet trainer aircraft were lost in three accidents from the local RAF base. In one accident the pilot failed to eject in time and died in the crash but in the other two acidents three pilots successfully ejected.

\section{CASE REPORTS}

\section{First accident}

In this accident two aircraft collided at relatively low altitude near a local village. Both pilots ejected, one aircraft crashed in a field and the other in a row of houses No (Fig. 1).

One pilot was seen at the site of the accident by the Station Medical Officer and

Correspondence: $\operatorname{Mr}$ M. R. James, Senior Registrar in Accident and Emergency, Royal Preston Hospital, Sharoe Green Lane, Fulwood, Preston, Lancashire, PR2 4HT, England. 


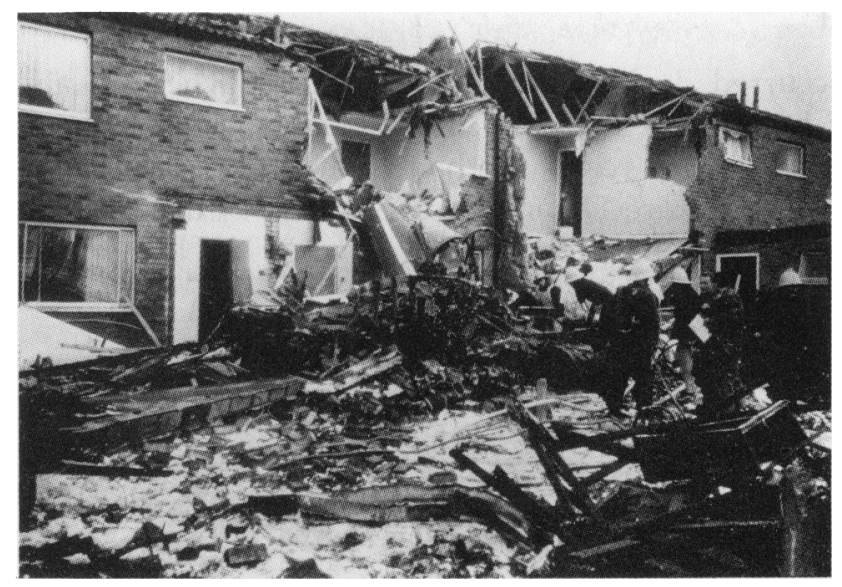

Fig. 1. To show the scene at the first accident.

transported to Lincoln A\&E department by private car. He had minor back pain and on examination slight tenderness over T5-T7 and grazes over both legs. Xrays revealed a crush fracture of $\mathrm{T} 5$ (Fig. 2).

The other pilot sustained a closed fracture of his right femur at the time of ejection but no back injury and was transported to Lincoln by RAF helicopter.



Fig. 2. To show the crush fracture of $\mathrm{T} 5$ in the pilot from the first accident. 


\section{Second accident}

This accident occurred during a formation take-off when an aircraft was forced into the ground by the slip-stream of the aircraft in front. The pilot ejected safely and walked away from the scene. He had burns to the face, chest and arms from the lead-sheathed Miniature Detonating Cord (MDC) used to shatter the canopy during ejection. He also had slight tenderness over the lower lumbar spine. X-ray showed a crush fracture of T12 (Fig. 3).

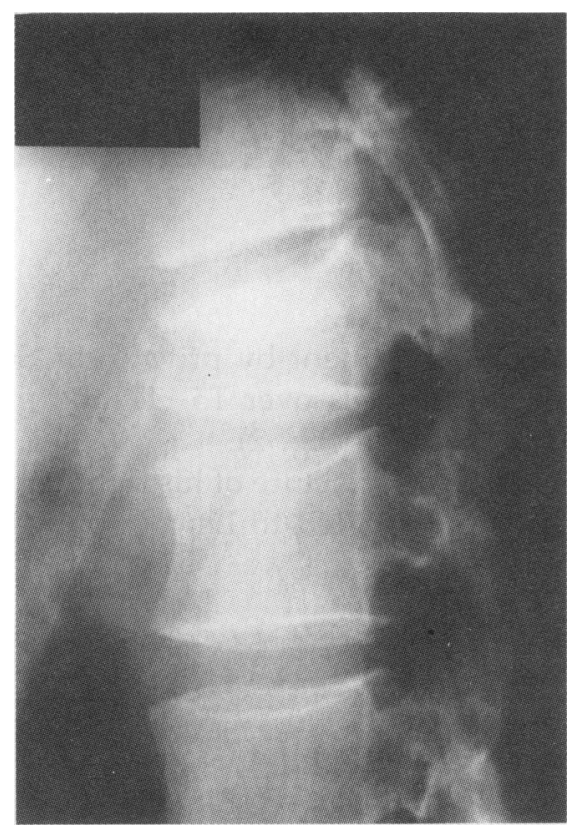

Fig. 3. To show the crush fracture of T12 in the pilot from the second accident.

\section{DISCUSSION}

Modern military aircraft operate at such speeds and low altitudes that it is necessary to have an assisted form of escape from a stricken aircraft - the ejection seat. All operational RAF aircraft are fitted with Martin Baker seats, which alone had saved over 5000 lives by 1986 . Because of the speed with which these seats need to leave the aircraft the forces on the aircrew are considerable. The older types of ejection seats operated by an explosive charge or charges blowing the seat clear of the aircraft. This resulted in very high rates of acceleration and rates of onset of acceleration (Jolt). More modern seats work with several charges and a rocket motor which results in a peak acceleration of $<15 \mathrm{G}$ at $<250 \mathrm{Gs}^{-1}$. A typical ejection sequence would be as in Table 1 . 
Table 1. To show a typical ejection sequence (simplified).

(1)

(6)
Seat pan handle operated by pilot

Gas cartridge operates harness restraints at shoulders and elbows, MDC fragments canopy

First charge blows seat up telescopic guide rails

Second charge blows seat clear of aircraft

Rocket motor accelerates seat to safe altitude

Seat separated from pilot and parachute deployed at safe altitude

Spinal injury may occur with ejection using any type of seat, but is commoner in the older designs $(70 \%)$ rather than the modern ones $(30 \%)$. Injury may be caused either during ejection or the subsequent landing. The incidence of spinal injury is increased if the peak acceleration is $>25 \mathrm{G}$ with a rate of onset of $>300 \mathrm{Gs}^{-1}$. The fractures may occur anywhere along the vertebral column but are commonest at the thoracolumbar junction where the vertebral end-plate has the highest loading per unit area. Fractures at the mid-thoracic level are also common. The fractures are usually anterior wedges but fracture-dislocations or burst fractures may occur.

It is not uncommon for pilots who have sustained these fractures to have minimal pain initially as in the two cases reported. For this reason it is a standing order in the RAF that all ejectees must have a full spinal radiographic screen. Most ejectees $(90 \%)$ who have sustained compression fractures make a full recovery and are flying aircraft fitted with ejection seats after 3 months convalescence.

It is unusual in this series that all the pilots sustained some injury. The two pilots with spinal fractures both ejected in a negative $G$ situation, so they will have been uncoupled from the seat, i.e. effectively hanging in the straps to a certain extent. As the ejection was initiated the seat will have hit them in the buttocks resulting in a sudden jolt rather than a more gradual acceleration, this has been shown to produce a greater incidence of spinal fractures. The pilot who sustained the femoral fracture may have sustained it for a similar reason in that the aircraft was in an unusual attitude at the time of ejection and his leg flailed and hit part of the cockpit or seat edge on exiting the aircraft. The burns from the molten lead around the MDC used to fragment the canopy are well documented and normally do not require any special treatment although corneal perforation has occurred in the past.

More severe injuries than those seen in these patients may occur when aircrew eject from aircraft at high speeds. Many of these injuries will be due to the windblast effect. Limbs may flail causing fractures and dislocations. The effect on the torso is similar to a fall from height onto water resulting in the ejectee being winded, sustaining subconjunctival haemorrhages and even ruptured viscii. 
244 M. R. James

\section{ACKNOWLEDGEMENTS}

I am grateful to Mr N. Pyrgos for permission to report his patients, Wing Commander D. J. Anton, RAF Institute of Aviation Medicine for his help with medical information and tracing references, and Martin-Baker Aircraft Company for their encouragement to prepare this report.

\section{REFERENCES}

Ernsting J. \& King P. (Eds) (1988) Aviation Medicine, 2nd edition. Butterworths, Sevonoaks, Kent. RAF Institute of Aviation Medicine, Aircrew Equipment Group Report No 529. The incidence of spinal fracture on Royal Air Force ejections 1968-1983.

The Editor apologizes for the delayed publication of this paper due to administrative error (originally submitted July 1989). 